\title{
BMJ Open Smoking in the home after childbirth: prevalence and determinants in an English cohort
}

\author{
Sophie Orton, ${ }^{1}$ Tim Coleman, ${ }^{1}$ Laura L Jones, ${ }^{2}$ Sue Cooper, ${ }^{1}$ Sarah Lewis ${ }^{3}$
}

To cite: Orton S, Coleman T, Jones LL, et al. Smoking in the home after childbirth: prevalence and determinants in an English cohort. BMJ Open 2015;5:e008856. doi:10.1136/bmjopen-2015008856

- Prepublication history and additional material for this paper is available online. To view these files please visit the journal online (http://dx.doi.org/10.1136/ bmjopen-2015-008856).

Received 21 May 2015 Revised 6 August 2015 Accepted 19 August 2015

CrossMark

\begin{abstract}
${ }^{1}$ UK Centre for Tobacco \& Alcohol Studies \& Division of Primary Care, University of Nottingham, Nottingham, UK ${ }^{2}$ UK Centre for Tobacco \& Alcohol Studies \& Unit of Public Health, Epidemiology \& Biostatistics, School of Health \& Population Sciences, University of Birmingham, Birmingham, UK

${ }^{3}$ UK Centre for Tobacco \& Alcohol Studies \& Division of Epidemiology \& Public Health, University of Nottingham, Nottingham, UK
\end{abstract}

Correspondence to

Sophie Orton;

Sophie.orton@nottingham. ac.uk

\section{ABSTRACT}

Objectives: Children's exposure to secondhand smoke (SHS) is causally linked to childhood morbidity and mortality. Over $38 \%$ of English children (aged 415) whose parents are smokers are exposed to SHS in the home. Little is known about the prevalence of SHS exposure in the homes of young infants ( $\leq 3$ months). This study aimed to estimate maternal self-reported prevalence of SHS exposure among infants of women who smoked just before or during pregnancy, and identify factors associated with exposure.

Setting: Primary Care, Nottingham, England.

Participants: Current and recent ex-smoking pregnant women $(\mathrm{n}=850)$ were recruited in Nottingham, England. Women completed questionnaires at 8-26 weeks gestation and 3 months after childbirth. Data on smoking in the home 3 months after childbirth was available for 471 households.

\section{Primary and secondary outcome measures:}

Maternal-reported smoking in the home 3 months after childbirth.

Results: The prevalence of smoking in the home 3 months after childbirth was $16.3 \%(95 \% \mathrm{Cl} 13.2 \%$ to $19.8 \%$ ) and after multiple imputation controlling for non-response $18.2 \%$ (95\% Cl $14.0 \%$ to $22.5 \%$ ). $59 \%$ of mothers were current smokers; of these, $24 \%$ reported that smoking occurred in their home compared to $4.7 \%$ of non-smokers. In multivariable logistic regression, mothers smoking $\geq 11$ cigarettes per day were 8.2 times ( $95 \% \mathrm{Cl} 3.4$ to 19.6) more likely to report smoking in the home. Younger age, being of non-white ethnicity, increased deprivation and less negative attitudes towards SHS were also associated with smoking in the home.

Conclusions: This survey of smoking in the home 3 months after childbirth found a lower prevalence than has been reported in older children. Interventions to support smoking mothers to quit, or to help them restrict smoking in the home, should target attitudinal change and address inequality relating to social disadvantage, younger age and non-white ethnic groups.

\section{BACKGROUND}

Exposure to secondhand smoke (SHS) is the involuntary inhalation of other people's

\section{Strengths and limitations of this study}

- This is the first survey since the introduction of smoke-free legislation, as far as we are aware, of smoking in the home immediately after childbirth.

- During recruitment, $96 \%$ of women attending selected antenatal clinics within Nottingham University Hospital Trust were screened for eligibility, accounting for around one-third of all births within Nottingham, England, during this time.

- The demographic profile of smokers within this cohort is similar to other UK pregnancy cohorts, meaning the sample is likely to be broadly representative.

- A potential limitation was the reliance on reported smoking measures.

- There were some differences between those who responded and those who did not respond at follow-up, however appropriate imputation methods were used to allow for this nonresponse bias.

cigarette smoke and globally, $40 \%$ of children are exposed. ${ }^{1}$ Children's SHS exposure has been causally linked to respiratory tract infections, middle ear disease, sudden unexplained death in infancy and asthma. ${ }^{2}$ The WHO believes that SHS is a substantial threat to child health, ${ }^{3}$ and the US Surgeon General argues there is no safe exposure level. ${ }^{4}$

In 2008, a study conducted in England reported $52 \%$ of children aged 4-15 whose parents were smokers were exposed to SHS in the home. ${ }^{5}$ This has reduced in recent years, with a reported $38.7 \%$ of children of smoking parents aged 4-15 years being exposed to SHS in the home in England in $2012,{ }^{6}$ however it clearly remains a significant problem. Similar trends have been observed elsewhere, both in the $\mathrm{UK}^{7-10}$ and internationally (eg, USA; ${ }^{11}{ }^{12}$ Ireland, France, Germany and the Netherlands ${ }^{13}$ ). However, current UK prevalence estimates for 
children's SHS exposure in the home focus on children aged $>4$ years, ${ }^{6-10}{ }^{14-16}$ and most studies include children aged $10-11$ years..$^{7-10} 16$ There is therefore little research examining SHS exposure in the home among young infants ( $\leq 3$ months) and few prevalence estimates. We are aware of only one UK study estimating the prevalence of SHS among young infants. Among children of smokers, $82 \%$ of infants (average age 3 months) experienced SHS exposure in the home. ${ }^{17}$ Elsewhere, we are aware of just two studies, from the USA, in which $10.8-21.4 \%$ of infants of smoking mothers aged $\leq 9$ months were exposed to SHS in the home ${ }^{18}$ and $24.5 \%$ were exposed to SHS for $\geq 1 \mathrm{~h}$ per day. ${ }^{19}$ Although these studies suggest SHS exposure may be a substantial issue, they were conducted prior to, ${ }^{17}{ }^{19}$ or around the time ${ }^{18}$ that comprehensive smoke-free legislations were introduced. There are no contemporary estimates of prevalence in this age group.

Additionally, of 41 studies investigating factors associated with children's SHS exposure in the home identified by systematic review, ${ }^{20}$ only three ${ }^{19} 2122$ included infants or children aged $<2$ years. This review found parental smoking, low socioeconomic status (SES) and being less educated were all consistently independently associated with children's SHS exposure in the home. ${ }^{20}$ However, due to the small number of studies focusing on younger age groups, little is known about the influences on SHS exposure in the home experienced by young infants; consequently, this paper reports the prevalence of SHS exposure among young infants born to women from an English pregnancy cohort, and identifies factors associated with this exposure.

\section{METHODS}

This study presents secondary analysis on data collected as part of the longitudinal cohort, the Pregnancy Lifestyle Survey (PLS); methods and cohort characteristics have been described in detail previously. ${ }^{23}$ The study received a favourable opinion from Derbyshire Research Ethics Proportionate Review Sub-Committee (reference 11/EM/0078).

\section{Participants}

The baseline sample size for the PLS was 850 , based on the cohort's primary aim to estimate the proportion of smokers who initiate quit attempts in the second or third trimester of pregnancy. ${ }^{23}$ Women who were aged $\geq 16$ years, between 8 and 26 weeks pregnant, and selfreported being current smokers or having smoked in the 3 months prior to pregnancy were eligible for participation.

\section{Recruitment and data collection}

Participants were recruited between August 2011 and August 2012 at two antenatal clinics within Nottingham University Hospitals NHS Trust, England. Participants completed a baseline questionnaire in the antenatal clinic when they were between 8 and 26 weeks gestation, and a follow-up questionnaire when their baby was 3 months old. At Follow-up, hospital administration staff obtained participants' delivery dates from their antenatal records. Participants were sent a questionnaire 3 months after their delivery date by post or email; if not returned, completion by telephone was attempted.

The questionnaires have been described elsewhere. ${ }^{23}$ In summary, both the baseline and the follow-up questionnaires were similar in format and content, using yes/no, multiple choice and five-point Likert items. The baseline questionnaire was divided into six sections: screening questions, health and pregnancy, smoking beliefs, current smoking behaviour, interest in getting help to stop smoking and sociodemographic information. At the 3-month follow-up, the same topics were covered but edited to reflect women's postnatal status. Additional questions about smoking in the home, and beliefs about harm caused to infants and children through SHS exposure were included.

\section{Outcomes}

The primary outcome measure was maternal-reported smoking by either themselves or someone else in their home 3 months after childbirth, using participants' responses to the questions 'how often do you smoke in your home nowadays?' and 'how often do other people smoke in your home nowadays?'. Responses used Likert items ranging from 1 ('never') to 5 ('very often'). A binary outcome was created, where participants who responded 'almost never' to 'very often' (2-5 on scale) to either of these questions were considered to have smoking in the home 3 months after childbirth, and participants who responded 'never' to have a smoke-free home.

The maternal sociodemographic characteristics of age, ethnicity, highest qualification, age left full-time education and current employment status were taken from baseline questionnaires. Age left full-time education was categorised as $\leq 16$ years (UK age of compulsory education), $\geq 16$ years and still in full-time education. Ethnicity was categorised as a binary variable (white British vs other ethnicity) due to small numbers of participants in non-white British ethnic groups. A measure of socioeconomic status (SES) was created by mapping participants' postcodes with corresponding 2007 Indices of Multiple Deprivation (IMD) scores, taken from routine UK Data Service data. ${ }^{24}$ The 2007 IMD measures a range of domains reflecting economic, social and housing issues, where higher scores reflect greater deprivation. Scores were divided into tertile groups.

Participant's self-reported smoking behaviour was measured at both time points. Women were categorised as being a non-smoker, or smoking $0-5,6-10, \geq 11$ cigarettes per day. Heaviness of smoking index (HSI) scores were calculated using the method described by 
Borland $e t a l^{25}$ Partner smoking status at 3 months after childbirth was categorised as non-smoker, smoker or not applicable/no partner.

Attitudes to children's SHS exposure were measured by asking participants the extent to which they agreed with four attitudinal statements using Likert items (figure 1). The items had high-internal consistency (Cronbach's $\alpha=0.9),{ }^{26}$ and so responses were combined into a single summed score (out of 20), whereby a higher score reflected a more negative attitude towards children's SHS exposure. Attitude scores were highly negatively skewed, and so were categorised into a binary variable; a score of $\geq 15$ represented 'negative attitudes towards child SHS exposure' and a score of $<15$ 'less negative attitudes towards child SHS exposure'.

\section{Data analysis}

Statistical analyses were conducted using Stata V.13. ${ }^{27}$ Cohort characteristics and the characteristics of responders and non-responders at 3 months after childbirth are presented, and differences examined using $\chi^{2}$ tests for categorical data and t tests for continuous data. The prevalence of smoking in the home was estimated using those with complete data; given that there was a high level $(50 \%)$ of missing data at 3 months after childbirth and observed differences in the characteristics of responders and non-responders, multiple imputation methods $^{28}$ were used to impute values for missing outcome data. Five imputed data sets were considered sufficient $^{29}$ and were constructed using the mi command in Stata, based on the following baseline variables: smoking behaviour, HSI, age, ethnicity, qualifications, employment, IMD score and partner smoking status. These variables were selected based on characteristics associated with child SHS exposure in the home in a previous systematic review ${ }^{20}$ and variables associated with non-response. ${ }^{30}$ The imputed outcome variable was only used for estimates of prevalence of smoking in the home; all other analyses were conducted using the original non-imputed outcome variable.

The variables smoking behaviour at baseline, smoking behaviour 3 months after childbirth, age, ethnicity, highest qualification, age left full-time education, employment status, IMD, partner smoking status and attitude towards child SHS exposure score were entered into a univariate logistic regression analysis and the ORs and $95 \%$ CI calculated. For continuous exposure variables, the linearity of the effect was tested using the likelihood-ratio test.

Those variables that were statistically significant in univariate analysis at the $\mathrm{p}<0.05$ level, or with strong a priori assumptions (eg, maternal education) based on the findings of a systematic review, ${ }^{20}$ were entered into exploratory multivariable logistic regression models. Correlations were observed between smoking behaviour at baseline, smoking behaviour at 3 months after childbirth and baseline HSI. Smoking behaviour at 3 months after childbirth was most strongly associated with the outcome measure, and was therefore included in the multivariable analyses and the other smoking variables omitted to avoid collinearity. Similarly, highest qualification and age left full-time education were considered in the multivariable analysis independently due to collinearity. Those variables reaching significance $(p<0.05)$ were retained in the model, and non-significant variables re-entered into the model sequentially. Participants with missing data for exposure variables were excluded from multivariable analysis $(\mathrm{n}=6)$. ORs, $95 \% \mathrm{CI}$, and likelihood ratio test $p$ values and Wald's $p$ values for trend for ordered categorical exposure variables are reported.

\section{RESULTS}

\section{Cohort characteristics}

The cohort consisted of 850 pregnant women, of which $56.6 \%$ were current smokers at baseline (table 1). The demographic profile of smokers within the cohort was similar to other UK pregnancy cohorts. ${ }^{23}$

\section{Follow-up response rates}

At follow-up, the response rate was $56 \%(\mathrm{n}=476)$ after non-response and withdrawal (figure 2). Owing to missing data in some of the returned questionnaires, smoking in the home information was available for 471 participants. Table 1 shows the characteristics of women who did and did not respond to the follow-up questionnaire 3 months after childbirth.
Figure 1 Attitudes to child secondhand smoke exposure scale items.
1) If my baby regularly breathes in people's tobacco smoke, it can seriously harm him/her

2) Smoking in the home can seriously harm babies (under 1 year old)

3) Smoking in the home can seriously harm children (over 1 year old)

4) Smoking in the home but not in the same room as a baby can seriously harm him/her

Rated using a 5-point Likert scale, 1 being 'not at all' and 5 being 'extremely' 
Table 1 Cohort characteristics and comparison between responders and non-responders at 3 months postnatal

\begin{tabular}{|c|c|c|c|c|}
\hline Characteristic & $\begin{array}{l}\text { All cohort } \\
\mathrm{N}(\%) \\
\mathrm{N}=850\end{array}$ & $\begin{array}{l}\text { Responders } \\
\text { at } 3 \text { months } \\
\text { postnatal } \\
\mathrm{N}(\%) \\
\mathrm{N}=476\end{array}$ & $\begin{array}{l}\text { Non-responders and } \\
\text { withdrawals at } \\
3 \text { months postnatal } \\
N(\%) \\
N=374\end{array}$ & $\mathrm{p}$ Value \\
\hline \multicolumn{5}{|l|}{ Smoking behaviour baseline } \\
\hline Recent ex-smoker & $362(43.4)$ & $235(50.1)$ & $127(34.7)$ & \\
\hline$\leq 5$ cigarettes per day & $191(22.9)$ & 105 (22.4) & $86(23.5)$ & \\
\hline $6-10$ cigarettes per day & $151(18.08)$ & $71(15.1)$ & $80(21.9)$ & \\
\hline$\geq 11$ cigarettes per day & $131(15.4)$ & $58(12.4)$ & $73(20.0)$ & $<0.0001$ \\
\hline Age (years) Mean (SD) & $25.8(5.5)$ & $26.5(5.6)$ & $24.8(5.3)$ & $<0.0001$ \\
\hline \multicolumn{5}{|l|}{ Ethnicity } \\
\hline White British & $751(89.0)$ & $421(89.0)$ & $330(89.0)$ & \\
\hline Other ethnicity & $93(11.0)$ & $52(11.0)$ & $41(11.1)$ & 0.0007 \\
\hline \multicolumn{5}{|l|}{ Highest qualification } \\
\hline No qualifications & 155 (18.2) & $62(13.0)$ & $94(25.1)$ & \\
\hline GCSEs or equivalent & $355(41.8)$ & $184(38.7)$ & $171(45.7)$ & \\
\hline AS/A-Levels or equivalent & $174(20.5)$ & $118(24.8)$ & $56(15.0)$ & \\
\hline Degree or equivalent & $133(15.7)$ & $95(20.0)$ & $38(10.2)$ & \\
\hline Other qualification & $33(2.9)$ & $17(3.6)$ & $16(4.3)$ & $<0.0001$ \\
\hline \multicolumn{5}{|l|}{ Age left education } \\
\hline$\leq 16$ years of age & $469(56.4)$ & $232(50.0)$ & $237(64.6)$ & \\
\hline$\geq 17$ years of age & $334(40.2)$ & $211(45.4)$ & $123(33.5)$ & \\
\hline Still in full-time education & $28(2.4)$ & $21(4.5)$ & $7(1.9)$ & $<0.0001$ \\
\hline \multicolumn{5}{|l|}{ Employment } \\
\hline Paid work, manual & $158(18.7)$ & $102(21.5)$ & $56(15.0)$ & \\
\hline Paid work, non-manual & $180(21.3)$ & $131(27.6)$ & $49(13.1)$ & \\
\hline $\begin{array}{l}\text { Paid work, unclear whether manual/ } \\
\text { non-manual }\end{array}$ & $45(5.3)$ & $27(5.7)$ & $18(4.8)$ & \\
\hline Unemployed & $201(23.7)$ & $92(19.4)$ & $109(29.2)$ & \\
\hline Full-time parent & 219 (25.9) & $97(20.5)$ & $122(32.7)$ & \\
\hline Full-time student & $23(2.7)$ & $13(2.7)$ & $10(2.7)$ & \\
\hline Other & $21(2.5)$ & $12(2.5)$ & $9(2.4)$ & $<0.0001$ \\
\hline \multicolumn{5}{|l|}{ Indices Multiple Deprivation score (IMD) ${ }^{*}$} \\
\hline 1st tertile & $284(33.6)$ & $178(37.4)$ & $106(28.8)$ & \\
\hline 2nd tertile & $279(33.1)$ & $162(34.0)$ & $117(31.8)$ & \\
\hline 3rd tertile & $281(33.3)$ & $136(28.6)$ & $145(39.4)$ & 0.002 \\
\hline \multicolumn{5}{|c|}{ Baseline heaviness of smoking index (smokers only) } \\
\hline Low addiction & $321(67.6)$ & $171(72.8)$ & $150(62.5)$ & \\
\hline Moderate addiction & $146(30.7)$ & $61(26.0)$ & $85(35.4)$ & \\
\hline High addiction & $8(1.7)$ & $3(1.3)$ & $5(2.1)$ & 0.06 \\
\hline \multicolumn{5}{|l|}{ Partner smoking baseline } \\
\hline Partner does not smoke tobacco & $499(59.1)$ & $172(36.4)$ & 122 (32.9) & \\
\hline Partner smokes tobacco & $294(34.8)$ & 279 (58.9) & $220(59.3)$ & \\
\hline No partner & $51(6.0)$ & $22(4.7)$ & $29(7.8)$ & 0.12 \\
\hline
\end{tabular}

Smoking in the home 3 months after childbirth:

\section{prevalence and determinants}

The 'raw' prevalence of smoking in the home 3 months after childbirth was $16.3 \%$ (95\% CI $13.2 \%$ to $19.8 \%$ ). At this time, $59 \%$ of mothers were current smokers; of these, $24 \%$ reported smoking in the home compared to $4.7 \%$ of non-smokers (table 2). After controlling for non-response bias using multiple imputation methods, prevalence of smoking in the home 3 months after childbirth was $18.2 \%$ (95\% CI $14.0 \%$ to $22.5 \%$ ).
Table 2 shows the results of univariate analysis for factors associated with smoking in the home 3 months after childbirth, using non-imputed data. The strongest observed associations were for maternal smoking at 3 months after childbirth; those mothers smoking $\geq 11$ cigarettes per day were 10.5 times more likely to report that smoking occurred in their home compared to nonsmoking mothers at this time point. Maternal age, ethnicity, highest qualification, age left full-time education, IMD, partner smoking status and attitudes towards child 
Figure 2 Consort diagram of response rates and reasons for withdrawal.

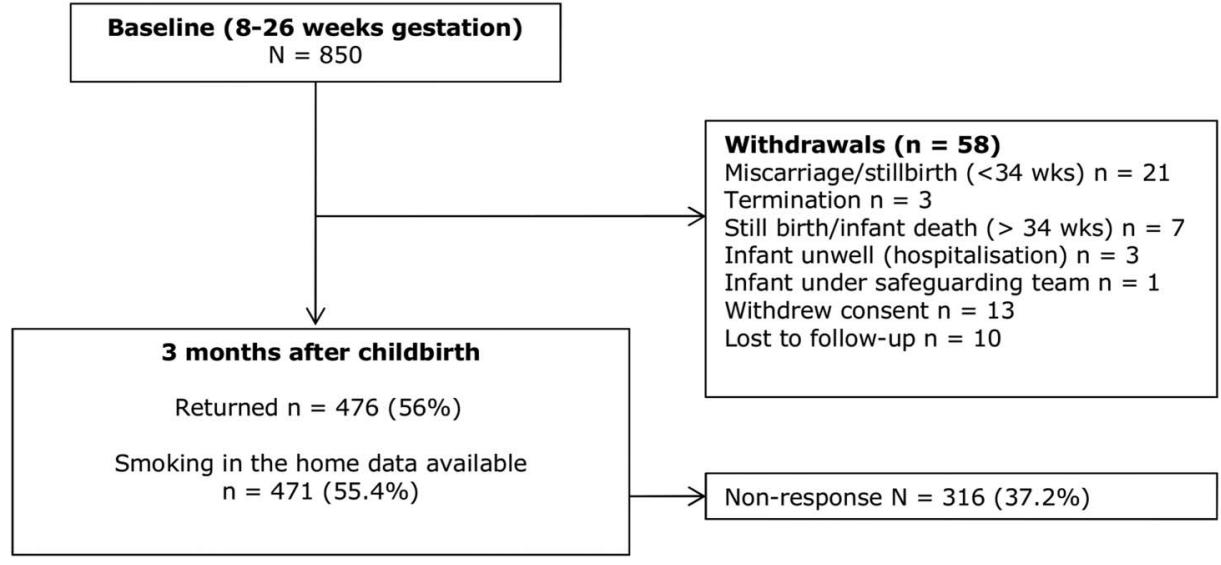

SHS exposure score were also significantly associated with smoking in the home in univariate analysis.

In exploratory multivariable logistic regression modelling, smoking behaviour at 3 months after childbirth, younger maternal age, being of non-white British ethnicity, being more deprived as measured by IMD and holding less negative attitudes towards child SHS exposure were significantly associated with smoking in the home 3 months after childbirth (table 2). The strongest observed association was for mothers who smoked $\geq 11$ cigarettes per day, who were over eight times more likely to report smoking occurred in their home.

\section{DISCUSSION}

After multiple imputation to control for non-response, the prevalence of smoking in the home at 3 months following childbirth was $18.2 \%$. Prevalence was higher in homes where mothers who smoked lived compared to those where mothers were non-smokers (24\% and $4.7 \%$, respectively). Mothers who were currently smoking $\geq 11$ cigarettes per day, younger, of non-white ethnicity, more deprived and held less negative attitudes towards child SHS exposure were significantly more likely to report that smoking occurred in their home 3 months after childbirth.

As far as we are aware, this is the first survey to investigate smoking in the home immediately after childbirth since the introduction of UK smoke-free legislation. Our estimate of the prevalence of SHS in the home was similar to estimates among slightly older infants from the USA, where $10.8-24.5 \%$ of infants of smoking mothers were exposed. ${ }^{18}{ }^{19}$ However, this was substantially lower than in the only previous UK survey in infants who were a similar age as those in our sample. ${ }^{17}$ In that study, $82 \%$ of infants aged on average 3 months old whose parents were smokers were exposed to SHS in the home. A number of factors are likely to have influenced our lower estimate of SHS exposure. Blackburn et $a l \mathrm{~s}^{17}$ study was conducted in 2003; smoke-free legislations have since been implemented across the UK and this may have increased awareness of SHS and its implications. Additionally, UK smoking prevalence has reduced since the earlier survey, in particular among those of childbearing age ${ }^{31}$; increasing numbers of UK households are reported as smoke-free ${ }^{2}$ and older children's SHS exposure in the home has reduced. ${ }^{5}{ }^{10}$ Together these factors suggest that rates of smoking in the home will have declined since Blackburn's study. ${ }^{17}$

The observed prevalence of young infant's SHS exposure in the home is much lower than the most recent estimates of prevalence among older children in England, where $38.7 \%$ of children aged 4-15 years whose parents were smokers were exposed in the home in 2012. ${ }^{6}$ This finding is positive; young infants are particularly susceptible to the risks of SHS exposure as they have a higher respiration rate ${ }^{32}$ and underdeveloped lungs. ${ }^{33}$ This is exacerbated further as young infants experience increased SHS exposure due to the amount of time spent indoors in close proximity to smoking parents and surfaces such as carpets that have been contaminated with smoke, and having more hand to mouth contact compared to older children. ${ }^{34}$ However, SHS exposure is dangerous for children of all ages ${ }^{2}$; it is not yet known at what age parents or carers start to consider their children to be less vulnerable to the effects of SHS exposure and relax their home smoking restrictions. The early postnatal period, where the prevalence of SHS exposure in the home appears greatly reduced, may be a significant time-point to prevent future SHS exposure, before smoking in the home becomes an established behaviour.

In a recent systematic review, ${ }^{20}$ children whose parents were smokers, of low SES, less educated or held less negative attitudes towards SHS were at an increased risk of SHS exposure in the home, with the largest risks observed for children living in households with smokers. With the exception of parental education, the factors associated with young infant's SHS exposure in this study are similar to those among older children. The findings also show similarities to the current limited evidence base examining this in infants aged $<2$ years elsewhere; in the USA, having more children in the household, being of white ethnicity, low maternal education, low maternal age, being unmarried, lower income and markers of disadvantage during pregnancy were associated with infant SHS exposure. ${ }^{18} 19$ 
Table 2 Prevalence of smoking in the home, and univariate and multivariable analysis of associated factors

\begin{tabular}{|c|c|c|c|c|}
\hline Characteristic & $\begin{array}{l}\text { All sample } \\
\text { ( } \mathrm{N}=471) \\
\mathrm{N} \text { (column \%) }\end{array}$ & $\begin{array}{l}\text { Smoking occurs } \\
\text { in the home } \\
(\mathrm{N}=76) \\
\mathrm{N}(\text { row \%) }\end{array}$ & $\begin{array}{l}\text { Unadjusted OR } \\
\text { OR }(95 \% \mathrm{Cl})\end{array}$ & $\begin{array}{l}\text { Adjusted OR } \\
(\mathrm{N}=465) \\
\text { OR }(95 \% \mathrm{Cl})\end{array}$ \\
\hline \multicolumn{5}{|l|}{ Smoking status baseline } \\
\hline Recent ex-smoker & $231(49.0)$ & $20(8.7)$ & Reference* $^{*}$ & \\
\hline Current smoker & $240(51.0)$ & $56(23.3)$ & 3.21 (1.86 to 5.60$)$ & \\
\hline \multicolumn{5}{|l|}{ Smoking behaviour baseline } \\
\hline Recent ex-smoker & $231(49.8)$ & $20(8.7)$ & Reference* $^{\star}$ & \\
\hline$\leq 5$ cigarettes per day & $104(22.4)$ & $19(18.3)$ & 2.36 (1.20 to 4.64$)$ & \\
\hline $6-10$ cigarettes per day & 71 (15.3) & $14(19.7)$ & 2.60 (1.23 to 5.45$)$ & \\
\hline$\geq 11$ cigarettes per day & $58(12.5)$ & $21(36.2)$ & 5.99 (2.96 to 12.12$)$ & \\
\hline \multicolumn{5}{|l|}{ Smoking status 3 months after childbirth } \\
\hline Ex-smoker & $192(40.8)$ & $9(4.7)$ & Reference* & \\
\hline Current smoker & 279 (59.2) & $67(24.0)$ & $6.43(3.12$ to 13.25$)$ & \\
\hline \multicolumn{5}{|c|}{ Smoking behaviour 3 months after childbirth } \\
\hline Ex-smoker & $192(40.8)$ & $9(4.7)$ & Reference* & Reference* \\
\hline$\leq 5$ cigarettes per day & $105(22.3)$ & $25(23.8)$ & 6.35 (2.84 to 14.23$)$ & $6.17(2.63$ to 14.46$)$ \\
\hline $6-10$ cigarettes per day & $83(17.6)$ & $11(13.3)$ & $3.11(1.24$ to 7.81$)$ & 2.09 (0.78 to 5.63$)$ \\
\hline$\geq 11$ cigarettes per day & $91(19.3)$ & $31(34.1)$ & 10.51 (4.73 to 23.32$)$ & 8.17 (3.41 to 19.55$)$ \\
\hline \multicolumn{5}{|l|}{ Baseline heaviness of smoking index } \\
\hline Low addiction & $171(36.3)$ & $35(20.5)$ & Reference* & \\
\hline Moderate addiction & $60(12.7)$ & $17(28.3)$ & $1.54(0.78$ to 3.01$)$ & \\
\hline High addiction & $3(0.6)$ & $2(66.7)$ & 7.77 (0.68 to 88.19$)$ & \\
\hline Not applicable/non-smoker & $237(50.3)$ & $22(9.28)$ & $0.40(0.22$ to 0.71$)$ & \\
\hline \multicolumn{5}{|l|}{ Maternal age (years) } \\
\hline Mean (SD) & $26.5(5.6)$ & $24.6(4.6)$ & $0.93(0.88 \text { to } 0.97)^{*}$ & $0.94(0.89$ to 1.00$) \dagger$ \\
\hline \multicolumn{5}{|l|}{ Ethnicity } \\
\hline White British & $416(88.9)$ & $62(14.9)$ & Reference $†$ & Reference $†$ \\
\hline Other ethnicity & $52(11.1)$ & $14(26.9)$ & $2.10(1.08$ to 4.11$)$ & $2.69(1.19$ to 6.06$)$ \\
\hline \multicolumn{5}{|l|}{ Highest qualification } \\
\hline No qualifications & $61(13.0)$ & $20(32.8)$ & Reference* $^{*}$ & \\
\hline GCSEs or equivalent & $183(38.9)$ & 28 (15.3) & 0.37 (0.19 to 0.72$)$ & \\
\hline AS/A-Levels or equivalent & $116(24.6)$ & $10(8.6)$ & 0.19 (0.08 to 0.45$)$ & \\
\hline Degree or equivalent & $94(20.0)$ & $11(11.7)$ & $0.27(0.12$ to 0.62$)$ & \\
\hline Other qualification & $17(3.6)$ & 7 (41.2) & $1.43(0.48$ to 4.33$)$ & \\
\hline \multicolumn{5}{|l|}{ Age left full-time education } \\
\hline$\geq 17$ years of age & $208(45.3)$ & $22(10.6)$ & Reference $†$ & \\
\hline$\leq 16$ years of age & $230(50.1)$ & 48 (20.9) & 2.23 (1.29 to 3.84$)$ & \\
\hline Still in full-time education & $21(4.6)$ & 3 (14.3) & 1.41 (0.38 to 5.17$)$ & \\
\hline \multicolumn{5}{|l|}{ Employment } \\
\hline Paid work, manual & $102(21.8)$ & $13(12.8)$ & Reference & \\
\hline Paid work, non-manual & $129(27.5)$ & $13(10.1)$ & $0.77(0.34$ to 1.74$)$ & \\
\hline $\begin{array}{l}\text { Paid work, unclear whether manual/ } \\
\text { non-manual }\end{array}$ & $27(5.8)$ & $6(22.2)$ & $1.96(0.67$ to 5.75$)$ & \\
\hline Unemployed & $90(19.2)$ & $21(23.3)$ & $2.08(0.97$ to 4.45$)$ & \\
\hline Full-time parent & $97(20.7)$ & $18(18.6)$ & $1.56(0.72$ to 3.39$)$ & \\
\hline Full-time student & $13(2.8)$ & $2(15.4)$ & $1.24(0.25$ to 6.26$)$ & \\
\hline Other & $11(2.4)$ & $3(27.27)$ & 2.57 (0.60 to 10.93$)$ & \\
\hline \multicolumn{5}{|l|}{ Indices Multiple Deprivation score (IMD) $\ddagger$} \\
\hline 1st tertile & $157(33.3)$ & $16(10.2)$ & Reference* & Reference $†$ \\
\hline 2nd tertile & 157 (33.3) & $17(10.8)$ & 1.07 (0.52 to 2.20$)$ & $1.03(0.47$ to 2.25$)$ \\
\hline 3rd tertile & 157 (33.3) & $43(27.4)$ & 3.32 (1.78 to 6.21$)$ & 2.30 (1.13 to 4.68$)$ \\
\hline \multicolumn{5}{|c|}{ Partner smoking at 3 months after childbirth } \\
\hline Partner does not smoke tobacco & $201(42.7)$ & $17(8.5)$ & Reference* & \\
\hline Partner smokes tobacco & $220(46.7)$ & $51(23.2)$ & 3.27 (1.82 to 5.88$)$ & \\
\hline No partner & $50(10.6)$ & $8(16.0)$ & 2.06 (0.83 to 5.09$)$ & \\
\hline
\end{tabular}


Table 2 Continued

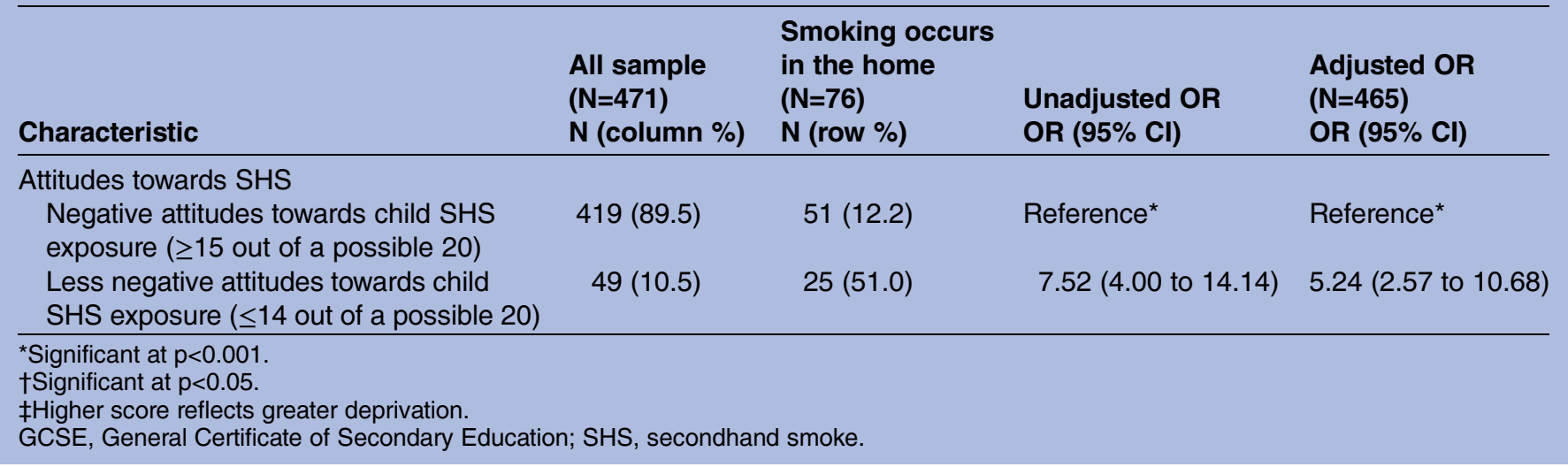

A strength of this study was that during recruitment, $96 \%$ of women attending selected antenatal clinics within Nottingham University Hospital Trust were screened for eligibility, accounting for around one-third of all births within Nottingham, England, during this time. ${ }^{23}$ The demographic profile of smokers within this cohort is similar to the composition of other UK pregnancy cohorts, ${ }^{23}$ meaning that the sample is likely to be broadly representative. A potential limitation of this research was the lack of power within analysis due to small numbers of participants in some exposure variable groups. Furthermore, there were some differences between those who responded and those who did not respond at follow-up, which are described. These differences may have impacted on our prevalence estimates, however appropriate imputation methods were used to allow for this non-response bias. Non-response biases are less likely to have impacted on estimates of association with smoking in the home. A further potential limitation was reliance on reported smoking measures; parents may be inclined to give socially desirable responses resulting in under-estimates of children's SHS exposure. ${ }^{35}$ However, maternal-reported SHS exposure has been found to correlate with urinary cotinine and home environmental nicotine ( $r$ range 0.3-0.6) in infants aged $<2.5$ years. ${ }^{36}$ As the cohort included only women who were current or recent ex-smokers during pregnancy, the prevalence estimate obtained does not reflect children's SHS exposure in the home in the general population. However, as parental smoking, and in particular maternal smoking within the home, is the primary source of children and infant's SHS exposure, ${ }^{20}$ this study gives a useful indication of the scale of young infant's SHS exposure.

While the demographic characteristics associated with smoking in the home after childbirth are not easily modifiable, they may help to inform which infants, parents or families are best targeted in future interventions. The findings highlight that the best way to prevent or reduce smoking in the home immediately after childbirth is to help smoking mothers to quit and stay abstinent after childbirth. However, a recent systematic review did not find a significant effect of any behavioural intervention approach to prevent postpartum smoking relapse, ${ }^{37}$ and as such more research is needed to identify interventions which can support women at this important time. Where women are unable or unwilling to quit smoking, making their home smoke-free is the next most effective way to protect children. ${ }^{38}$ This study, consistent with research in older children, ${ }^{20}$ shows that less negative attitudes towards SHS exposure is associated with smoking in the home after childbirth. Interventions targeting attitudes towards SHS by supporting parents to recognise the benefits of protecting children from SHS may therefore be useful to promote smoke-free homes.

\section{CONCLUSIONS}

The prevalence of smoking in homes where young infants live is lower than has been reported in older children ( $>3$ months), suggesting that the early postnatal period may be an ideal time to intervene to prevent future SHS exposure in the home. The factors associated with smoking in the home immediately following childbirth were similar to those previously reported among older children. Interventions to support smoking mothers to quit, or to help them restrict smoking in the home, should target attitudinal change and address inequality relating to social disadvantage, younger age and non-white ethnic groups.

Acknowledgements The authors would like to thank Nottingham University Hospital NHS Trust for facilitating this research. The authors also thank Katharine Bowker, Rachel Whitemore, Felix Naughton, Michael Ussher, Kate E Pickett, Jo Leonardi-Bee and Stephen Sutton for their invaluable input and assistance in the Pregnancy Lifestyle Survey.

Contributors S0, TC, LLJ, SC and SL conceived and designed the experiments. SO performed the experiments. SO and SL analysed the data. SO, TC, LLJ, SC and SL wrote the paper. All authors read and approved the final manuscript.

Funding $\mathrm{SO}$ is funded by the National Institute for Health Research (NIHR) School for Primary Care Research (NIHR SPCR). The NIHR SPCR is a partnership between the Universities of Birmingham, Bristol, Keele, Manchester, Nottingham, Oxford, Southampton and University College 
London. This article presents independent research funded by the NIHR under the Programme Grants for Applied Research programme (RP-PG-0109-10020). The views expressed are those of the author(s) and not necessarily those of the NHS, the NIHR or the Department of Health.

Competing interests None declared.

Ethics approval Derbyshire Research Ethics Proportionate Review Sub-Committee.

Provenance and peer review Not commissioned; externally peer reviewed.

Data sharing statement No additional data are available.

Open Access This is an Open Access article distributed in accordance with the terms of the Creative Commons Attribution (CC BY 4.0) license, which permits others to distribute, remix, adapt and build upon this work, for commercial use, provided the original work is properly cited. See: http:// creativecommons.org/licenses/by/4.0/

\section{REFERENCES}

1. Oberg M, Jaakkola MS, Woodward A, et al. Worldwide burden of disease from exposure to second-hand smoke: a retrospective analysis of data from 192 countries. Lancet 2011;377:139-46.

2. Royal College of Physicians. Passive smoking and children. A report of the Tobacco Advisory Group of the Royal College of Physicians. Secondary Passive smoking and children. A report of the Tobacco Advisory Group of the Royal College of Physicians, 2010. https:// www.rcplondon.ac.uk/sites/default/files/documents/ passive-smoking-and-children.pdf (accessed 12 Jan 2015).

3. World Health Organisation. International Consultation on Environmental Tobacco Smoke (ETS) and Child Health, Consultation Report. Secondary International Consultation on Environmental Tobacco Smoke (ETS) and Child Health, Consultation Report, 1999. http://www.who.int/tobacco/research/en/ ets_report.pdf, (accessed 12 Jan 2015).

4. US Department of Health and Human Services. The Health Consequences of Smoking-50 Years of Progress: a Report of the Surgeon General. Secondary The Health Consequences of Smoking -50 Years of Progress: A Report of the Surgeon General, 2014. http://www.surgeongeneral.gov/library/reports/50-years-of-progress/ full-report.pdf (accessed 08 Jan 2015).

5. Jarvis MJ, Sims M, Gilmore A, et al. Impact of smoke-free legislation on children's exposure to secondhand smoke: cotinine data from the Health Survey for England. Tob Control 2011;21:18-23.

6. Jarvis MJ, Feyerabend C. Recent trends in children's exposure to second-hand smoke in England: cotinine evidence from the Health Survey for England. Addiction 2015;110:1484-92.

7. Akhtar PC, Haw SJ, Currie DB, et al. Smoking restrictions in the home and secondhand smoke exposure among primary schoolchildren before and after introduction of the Scottish smoke-free legislation. Tob Control 2009;18:409-15.

8. Akhtar PC, Haw SJ, Levin KA, et al. Socioeconomic differences in second-hand smoke exposure among children in Scotland after introduction of the smoke-free legislation. J Epidemiol Community Health 2010;64:341-6.

9. Moore GF, Holliday JC, Moore LA. Socioeconomic patterning in changes in child exposure to secondhand smoke after implementation of smoke-free legislation in Wales. Nicotine Tob Res 2011;13:903-10.

10. Moore GF, Moore L, Littlecott HJ, et al. Prevalence of smoking restrictions and child exposure to secondhand smoke in cars and homes: a repeated cross-sectional survey of children aged 10-11 years in Wales. BMJ Open 2015;5:e006914.

11. Pirkle JL, Bernert JT, Caudill SP, et al. Trends in the exposure of nonsmokers in the US population to secondhand smoke: 19882002. Environ Health Perspect 2006:853-8.

12. Centers for Disease Control Prevention (CDC). Disparities in secondhand smoke exposure-United States, 1988-1994 and 1999-2004. MMWR Morb Mortal Wkly Rep 2008;57:744-7.

13. Mons $\mathrm{U}$, Nagelhout $\mathrm{GE}$, Allwright $\mathrm{S}$, et al. Impact of national smoke-free legislation on home smoking bans: findings from the
International Tobacco Control Policy Evaluation Project Europe Surveys. Tob Control 2013;22(e1):e2-9.

14. Alwan N, Siddiqi $\mathrm{K}$, Thomson $\mathrm{H}$, et al. Children's exposure to second-hand smoke in the home: a household survey in the North of England. Health Soc Care Community 2010;18:257-63.

15. Sims M, Tomkins S, Judge K, et al. Trends in and predictors of second-hand smoke exposure indexed by cotinine in children in England from 1996 to 2006. Addiction 2010;105:543-53.

16. Whitrow MJ, Harding S, Maynard MJ. The influence of parental smoking and family type on saliva cotinine in UK ethnic minority children: a cross sectional study. BMC Public Health 2010;10:262.

17. Blackburn C, Spencer N, Bonas S, et al. Effect of strategies to reduce exposure of infants to environmental tobacco smoke in the home: cross sectional survey. BMJ 2003;327:257.

18. Gibbs FA, Tong VT, Farr SL, et al. Smoke-free-home rules among women with infants, 2004-2008. Prev Chronic Dis 2012;9:E164.

19. Hawkins SS, Berkman L. Identifying infants at high-risk for secondhand smoke exposure. Child Care Health Dev 2013;40:441-5.

20. Orton S, Jones LL, Cooper S, et al. Predictors of children's secondhand smoke exposure at home: a systematic review and narrative synthesis of the evidence. PLOS ONE 2014;9:e112690.

21. Anuntaseree W, Mo-Suwan L, Ma A-Lee A, et al. Prevalence and associated factors of passive smoking in Thai infants. Prev Med 2008;47:443-6.

22. Baheiraei $\mathrm{A}$, Kharaghani $\mathrm{R}$, Mohsenifar $\mathrm{A}$, et al. Factors associated with secondhand smoke exposure in infants. Tanaffos 2010;9:43-9.

23. Orton S, Bowker K, Cooper S, et al. Longitudinal cohort survey of women's smoking behaviour and attitudes in pregnancy: study methods and baseline data. BMJ Open 2014;4:e004915.

24. UK Data Service. UK Data Service. Secondary UK Data Service, 2014. http://ukdataservice.ac.uk/ (accessed 14 Nov 2014).

25. Borland R, Yong HH, O'Connor RJ, et al. The reliability and predictive validity of the Heaviness of Smoking Index and its two components: findings from the International Tobacco Control Four Country study. Nicotine Tob Res 2010;12(Suppl):S45-50.

26. Cronbach LJ. Coefficient alpha and the internal structure of tests. Psychometrika 1951;16:297-334.

27. Stata Statistical Software: Release 13 [program]. College Station, TX: StataCorp LP., 2013.

28. Spratt M, Carpenter J, Sterne JA, et al. Strategies for multiple imputation in longitudinal studies. Am J Epidemiol 2010;172:478-87.

29. Schafer JL. Multiple imputation: a primer. Stat Methods Med Res 1999;8:3-15.

30. Arnold AM, Kronmal RA. Multiple imputation of baseline data in the cardiovascular health study. Am J Epidemiol 2003;157:74-84.

31. Office for National Statistics. Adult Smoking Habits in Great Britain, 2013. Secondary Adult Smoking Habits in Great Britain, 2013. 2014. http://www.ons.gov.uk/ons/dcp171778_386291.pdf (accessed 06 Jan 2015).

32. Fleming S, Thompson M, Stevens R, et al. Normal ranges of heart rate and respiratory rate in children from birth to 18 years of age: a systematic review of observational studies. Lancet 2011;377:1011-18.

33. Burri PH. Fetal and postnatal development of the lung. Annu Rev Physiol 1984;46:617-28.

34. Matt GE, Quintana PJ, Hovell MF, et al. Households contaminated by environmental tobacco smoke: sources of infant exposures. Tob Control 2004;13:29-37.

35. Matt GE, Wahlgren DR, Hovell MF, et al. Measuring environmental tobacco smoke exposure in infants and young children through urine cotinine and memory-based parental reports: empirical findings and discussion. Tob Control 1999;8:282-9.

36. Matt GE, Hovell MF, Zakarian JM, et al. Measuring secondhand smoke exposure in babies: the reliability and validity of mother reports in a sample of low-income families. Health Psychol 2000;19:232-41.

37. Hajek P, Stead LF, West R, et al. Relapse prevention interventions for smoking cessation. Cochrane Database Syst Rev 2013;8: CD003999.

38. Winkelstein ML, Tarzian A, Wood RA. Parental smoking behavior and passive smoke exposure in children with asthma. Ann Allergy Asthma Immunol 1997;78:419-23. 